\title{
0 cotidiano, o lúdico e as redes relacionais: a artesania do cuidar em terapia ocupacional no hospital ${ }^{*}$
}

\author{
Andrea do Amparo Carotta de Angeli ${ }^{1}$ \\ Nathália Azevedo Luvizaro² \\ Sandra Maria Galheigo ${ }^{3}$
}

\section{Introdução}

O hospital é um lugar de cuidado de maior complexidade, cuja intensidade é medida em relação à gravidade do adoecimento. A urgência, a dor e o sofrimento agudos, a iminência da morte, o desconhecido acerca de seu próprio corpo, a impotência e a necessidade do outro atravessam e constituem este território instável, intenso do cotidiano hospitalar para todos os seus atores.

Profissionais e usuários são mergulhados em um dia a dia distinto do que habitualmente experimentam em suas vidas. Elementos comuns e constituintes de seus cotidianos são regidos por outras ordens, exteriores aos desejos dos sujeitos. O comer, o dormir e o vestir-se, por exemplo, se organizam em torno das rotinas de procedimentos e necessidades de cuidado definidas pelos saberes e práticas dos profissionais de saúde. O sujeito pode vivenciar uma expropriação de seu corpo e da gestão de seu cotidiano, uma ruptura com a continuidade de sua vida, de seus vínculos sociais e afetivos. Acontece, assim, a construção de uma tessitura cotidiana muito particular que reitera, a todo o tempo, o exclusivo lugar de paciente; lugar onde as relações se estabelecem de maneira assimétrica, atravessadas por diferenças importantes no poder contratual entre técnicos da saúde e sujeitos do cuidado. Na contramão desta lógica, vêm se construindo diferentes ações que visam a humanização e a produção de cuidado pautadas pelos princípios da integralidade.

Neste sentido, novas estratégias começam a se desenvolver de forma a resgatar para o sujeito o lugar de protagonista das ações em saúde, e a desenvolver uma cotidianidade diferenciada nos ambientes hospitalares que reinscreva o processo de adoecimento como parte integrante da vida: percursos que evitem uma cisão entre saúde e doença, internação e vida cotidiana.

O período de internação pode, inclusive, ser aproveitado para apoiar o paciente na direção de conquistar maior autonomia e na reconstrução de seu modo de andar a vida. (Cecílio, Merhy, 2003, p.204)

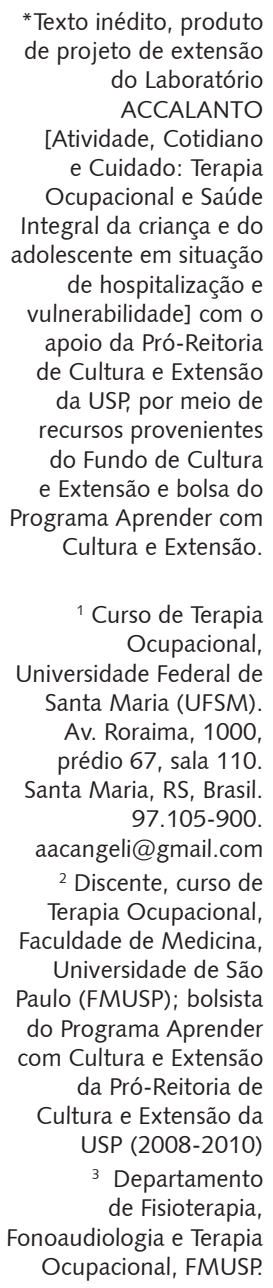

*Texto inédito, produto de projeto de extensão do Laboratório ACCALANTO [Atividade, Cotidiano e Cuidado: Terapia Ocupacional e Saúde Integral da criança e do adolescente em situação de hospitalização e vulnerabilidade] com o apoio da Pró-Reitoria de Cultura e Extensão da USP, por meio de recursos provenientes do Fundo de Cultura e Extensão e bolsa do Programa Aprender com Cultura e Extensão.

${ }^{1}$ Curso de Terapia Ocupacional,

Universidade Federal de Santa Maria (UFSM). Av. Roraima, 1000, prédio 67, sala 110. Santa Maria, RS, Brasil. 97.105-900.

aacangeli@gmail.com

2 Discente, curso de Terapia Ocupacional, Faculdade de Medicina, Universidade de São Paulo (FMUSP); bolsista do Programa Aprender com Cultura e Extensão da Pró-Reitoria de Cultura e Extensão da USP (2008-2010) 3 Departamento de Fisioterapia, Fonoaudiologia e Terapia Ocupacional, FMUSP. 
Produzir intervenções e dispositivos de cuidado em terapia ocupacional que observem a complexidade do cotidiano, suas significações e ações para os sujeitos requer a invenção de tecnologias específicas para o ambiente hospitalar. Há que se observar que o cotidiano se refere a uma infinidade de ações que permitem aos sujeitos ser, fazer e estar no mundo de modo particular. Há uma linguagem própria a cada um, a cada grupo familiar, cultural e social, que se traduz pelos objetos, modos de dizer e de agir, de confraternizar, trocar e compartilhar afetos e matérias.

Ao atentarmos para o que constitui o universo da infância/adolescência, observamos que é por meio da atividade lúdica que se apreende, dialoga, conhece e inventa um lugar de existir no mundo. Ao brincar, a criança está "constituindo mundos e estabelecendo a possibilidade de transformar a realidade dada por meio de seu gesto [...] instituir modos de ser" (Safra, 2006, p.130). O brincar se refere, assim, à linguagem que institui e fundamenta o cotidiano da criança, ao mesmo tempo em que Ihe permite projetar futuros, sonhar.

A brincadeira é a língua com a qual a criança se comunica e constitui seu cotidiano, explora o corpo, os objetos, a expressão, as ações, de modo a colocar em jogo seus sentidos dados, refazer trajetos e histórias. Tece brincando, portanto, o seu dia a dia. É por meio da experimentação desta língua que o cuidado em saúde pode vir a acontecer de modo que crianças e adolescentes possam ser protagonistas de seu processo saúde-doença, apropriando-se de sua condição de modo afirmativo, não como vítima dos acontecimentos, mas como oportunidade de reinvenção de si e de seu lugar no mundo.

Baseado nesses princípios e nas diretrizes das políticas de saúde e de humanização, o Laboratório ACCALANTO da Universidade de São Paulo vem desenvolvendo projetos de ensino, pesquisa e extensão sobre os processos de hospitalização na infância e adolescência e os modos de cuidar em terapia ocupacional.

O ACCALANTO compartilha das concepções de Merhy $(2002,2000)$ acerca da construção de um trabalho vivo em ato. Este, para o autor, engendra diferentes campos de saberes para a produção de saúde e de cuidado, produzindo e usando, para tanto, diversas tecnologias: a dura, que se refere aos equipamentos e procedimentos de denso desenvolvimento técnico-científico; a leve-dura, que contempla a organização e a aplicação de conhecimentos estruturados e protocolados; e a leve, que ocorre no espaço intersubjetivo entre profissional e usuário, sendo essencialmente relacional e processual. Esta abrange a escuta, o acolhimento, as expectativas, afetações e processos vinculares provocados pelo encontro dos atores envolvidos.

Apoiado na compreensão de que as práticas de cuidado em terapia ocupacional no ambiente hospitalar devem contemplar essas diferentes tecnologias, o ACCALANTO vem construindo modos de cuidar que articulam uma combinação de recursos e delicadezas na atenção, que compreende: a escuta de um familiar, a produção de móbiles com as mães para os ambientes dos bebês, a execução de manobras para a diminuição da limitação de movimentos ou a utilização de tecnologia assistiva. Acredita-se que uma combinação tecnológica adequada resulte em qualidade e integralidade da assistência, prevenindo riscos e adoecimento, facilitando a vida e a autonomia do usuário. Assim, "o cotidiano adquire natureza de produção de realidades, trabalho vivo em ato, constituidor de mundo, território de disputa com as ditas forças externas por forças de criação" (Cecim, Merhy, 2009, p.533).

O projeto de extensão do Laboratório ACCALANTO desenvolve estratégias de cuidado em terapia ocupacional em uma enfermaria pediátrica, a partir de uma metodologia de trabalho em processo em que as ações se (re)definem de acordo com as necessidades singulares de crianças-adolescentescuidadores na internação hospitalar. O ACCALANTO se estrutura a partir de eixos do cuidado - Ninar, Aquarela e Teias. Os eixos Ninar e Aquarela destinam-se, respectivamente, às idades de zero a dois anos e de três a 15 anos, tratando aqueles que necessitam de atendimento focalizado de maior complexidade, por meio de variadas tecnologias de cuidado e de estruturação da rede de cuidados e de suporte. O eixo Ninar busca também a ampliação dos repertórios de cuidado de pais/cuidadores, visando favorecer a atenção às necessidades físicas e emocionais do bebê e seu desenvolvimento pleno (Galheigo, Angeli, 2008).

O eixo Teias, objeto de relato deste artigo, responde pela promoção de atividades lúdicas na enfermaria pediátrica, de modo a propiciar uma cotidianidade diferenciada nesse espaço e ofertar 
ampliação ou resgate de aspectos importantes à saúde integral da criança e do adolescente, contribuindo para a ambiência, a convivência e a humanização do cuidado. Oferece oficinas de atividades, como a de contação de histórias para as crianças e adolescentes, sem demanda de atendimento focalizado, envolvendo familiares e profissionais. Os atendimentos individuais e grupais buscam possibilitar a reinvenção de si, o desenvolvimento do protagonismo, a apropriação do cotidiano no contexto da internação e a construção de redes de sustentabilidade relacional intrahospitalar e extra-hospitalar.

Este trabalho tem como objetivo refletir sobre os modos de fazer, de sentir e conduzir as ações de contar histórias na enfermaria pediátrica. A reflexão, realizada a partir de revisão bibliográfica e anotações de diário de campo do projeto, se pauta pelos norteadores teóricos baseados na humanização do cuidado (Deslandes, 2006; Benevides, Passos, 2005) e suas tecnologias (Merhy, 2002, 2000), e considerando o brincar no contexto das intervenções no hospital.

\section{O lúdico, a terapia ocupacional e a interdisciplinaridade no hospital}

A atividade lúdica no contexto hospitalar tem sido vista como recurso multidisciplinar, passível de uso pelos profissionais de saúde (Pedrosa et al., 2007; Furtado, 1999; Morais, 1999). Entretanto, a discussão da interdisciplinaridade é pouco incorporada à reflexão sobre o uso da atividade lúdica como recurso terapêutico (Mitre, Gomes, 2007).

A literatura aponta para a compreensão de que a atividade lúdica é um veículo fundamental de comunicação e ajuda crianças e adolescentes hospitalizados. Acredita-se que o lúdico facilite e melhore as condições de saúde-doença-cuidado dos envolvidos no processo de hospitalização, sejam familiares, profissionais de saúde e/ou sujeitos da atenção. Afinal, no contexto hospitalar, o sujeito vivencia situações potencialmente traumáticas, como: a separação das pessoas com as quais possui vínculo afetivo, a mudança de espaço físico e dos modos de experimentação e exploração do mundo, além de procedimentos terapêuticos invasivos e dolorosos. Para Rossit e Kovacs (1998), o brincar pode devolver a condição de atividade (em oposição à passividade) a partir da possibilidade de reinvenção do real, transformando-o numa experiência possível do viver. A promoção do brincar possibilita integrar a experiência de estar no hospital como parte da vivência da criança, o que pode minimizar os impactos da internação em seu cotidiano, desenvolvimento e trocas sociais.

A atividade lúdica, para Kishimoto (1996), estimula a representação e a expressão de conteúdos que invocam aspectos da realidade, podendo constituir-se como intermediadora da relação da criança com o mundo externo. Ao brincar, a criança entra em contato com a realidade em uma linguagem comum a ela, facilitando sua apreensão e recriação. Em consonância com o pensamento winnicottiano, Brougère (2002) afirma que o brincar possibilita uma relação aberta e positiva com a cultura, a partir da qual o sujeito pode se desenvolver criativa e espontaneamente. Winnicott (1975) compreende e valoriza a experiência lúdica, enquanto constituinte da saúde da criança, ao convidar que se observe o ambiente vincular onde se insere. Aponta que o ambiente, embora possa oscilar de acordo com as necessidades da criança, deve ser contínuo, previsível e acolhedor, sobretudo nos momentos de maior fragilidade. A tessitura vincular é imprescindível para o desenvolvimento da continuidade do ser de forma espontânea e criativa, e o estado de jogo inerente à atividade lúdica figura como a língua na qual mergulham seus atores na criação permanente de si e do mundo que habitam. Nestas tramas vinculares transitam elementos da cultura, dos códigos sociais e familiares, elementos da vida subjetiva que serão (re)organizados, transformados pela criatividade. Estado de criação permanente que garante e perpetua a condição de saúde dos sujeitos.

Autores mostram a importância de se facilitar o brincar como forma de garantir que o ambiente e a realidade externa não invadam o ser, dando visibilidade aos prejuízos possíveis que a rotina hospitalar, marcada por procedimentos e organizações exteriores às dimensões subjetivas dos sujeitos, pode gerar. A linguagem da brincadeira, sendo recurso seguro e acessível à criança, permite seu domínio das diferentes situações pela fantasia, o que subsidia uma adaptação positiva e ativa na vivência da rotina hospitalar (Morais, 1999). 
De posse da compreensão de que o ambiente é composto por elementos subjetivos e socioculturais, Brougère (2002) afirma que o brincar é uma atividade que possui significações sociais diversas e necessita ser aprendido, fato que ocorre no próprio ato de brincar. Segundo o autor, " $[. .$. quando se brinca se aprende antes de tudo a brincar, a controlar um universo simbólico particular" (Brougère, 2002, p.23). Desse modo, ao mesmo tempo em que o sujeito se serve de elementos culturais para construir sua própria cultura lúdica, também a constitui de significações singulares.

A criança, na maior parte das vezes, não se contenta em contemplar ou registrar as imagens: ela as manipula na brincadeira e, ao fazê-lo, transforma-as e lhes dá novas significações. [...]. O valor lúdico reforça a eficácia simbólica do brinquedo. É isso que faz a especificidade do brinquedo em relação a outros suportes culturais: a relação ativa introduzida pela criança. (Brougère, 1995, p.47-8)

Neste sentido, o hospital pode abrir-se como um espaço de acesso e manipulação de conteúdos diversos - não somente lugar de dor, incômodo e restrição - permitindo a modificação da realidade e de valores socioculturais. Este deslocamento e complexificação do lugar do hospital e, consequentemente, das ações e lugares dos profissionais de saúde configuram-se também como estratégia de intervenção política. O brincar abre, para crianças e adolescentes, mas também para todos os demais envolvidos no processo, a condição permanente de reinventar o presente, a realidade e a si mesmo.

A atividade lúdica figura como interessante e potente recurso para a emergência de sentimentos, medos e ansiedades de difícil expressão e elaboração, constituindo-se, portanto, como estratégia de enfrentamento das complicações e dificuldades vividas na internação (Morais, 1999). Para esta autora, o brincar pode também instaurar outras formas possíveis de comunicação e de relação, instrumentalizando o profissional de saúde para lidar com as crianças, os adolescentes e os familiares em situação de maior fragilidade. Assim, o sujeito deve ser percebido para além de sua condição de doença e a intervenção deve contemplar recursos que permitam a expressão e a elaboração da experiência do adoecimento e da hospitalização, e não somente a aplicação de técnicas de reabilitação (Pengo, Santos, 2004).

Mitre e Gomes (2004) problematizam os sentidos da promoção do brincar como ação de saúde: sendo associado à condição de saúde, o brincar devolve à criança a própria condição da infância, permite e valoriza a troca de saberes a partir da instauração de um espaço mais democrático. Como recurso interdisciplinar, facilita a interação entre os profissionais de saúde, as crianças e os acompanhantes, abrindo a possibilidade da "[...] promoção do brincar no espaço da hospitalização infantil como facilitador de uma dinâmica de interações que (re)significa o modelo tradicional de intervenção e cuidado de crianças hospitalizadas" (Mitre, Gomes, 2004, p.8).

Rever aquilo que constitui o cotidiano, suas tramas vinculares, seus ritmos e ações, que vão desenhando um lugar, modos de pensar, de agir, de exprimir, de comunicar, permite um deslocamento do pensamento da relação adoecimento-recurso terapêutico adequado (Castro, 2005). Nesse sentido, o terapeuta ocupacional é convidado a observar o ambiente hospitalar para entender as particularidades que o compõem, as sutilezas de suas relações com as coisas e entre as pessoas. Assim, acessa valores intrínsecos aos modos de comunicar e agir, para poder inserir-se e potencializar os sentidos de ser criança, adolescente, adulto-cuidador, sujeito-trabalhador-de-saúde.

O ACCALANTO vem produzindo suas estratégias de ação dentro das tramas cotidianas que compõem a enfermaria pediátrica, com olhos dirigidos ao que se traduz como infância e adolescência, tomando a atividade lúdica como a língua que se fala na infância, mas também que traduz valores socioculturais de um povo, que produz coletividades e tece um cotidiano. Para tanto, pesquisa e experimenta procedimentos em terapia ocupacional no contexto dos processos de hospitalização, como o uso de oficinas de contação de histórias. 


\title{
Artesanias do cuidar: o cotidiano, o lúdico e as redes relacionais
}

\author{
Era a chapeuzinho amarelo. \\ Amarelada de medo. \\ Tinha medo de tudo, \\ aquela chapeuzinho. \\ Já não ria. \\ Em festa não aparecia. \\ Não subia escada \\ nem descia. \\ Não estava resfriada \\ mas tossia. \\ Ouvia conto de fada \\ e estremecia. \\ Não brincava mais de nada, \\ nem de amarelinha. \\ (Buarque, 2006, s/p)
}

Contar histórias. Como é que se conta uma história? O que acontece quando um livro se abre, se narra um evento, se fazem imagens com as palavras, objetos, gestos? Qual sua relação com a produção de saúde?

A oficina de contação de histórias tornou-se uma estratégia importante do ACCALANTO no atendimento às crianças, aos adolescentes e seus cuidadores, usando, para este fim, o espaço da brinquedoteca e áreas de convivência da enfermaria. O trabalho tinha como metodologia a construção de uma ambiência - lugar objetivo e simbólico onde elementos diversos (brinquedos, objetos, histórias, jogos) eram colocados e distribuídos para que a ação pudesse acontecer - e de um estado de prontidão do terapeuta ocupacional. Este devia acolher o acaso, o inusitado e a necessidade de improvisar no contato com diferentes elementos e sujeitos. De posse do ato de contar histórias, e de ter "histórias na manga", reuníamos o grupo na enfermaria, mobilizando-o a participar de uma ação lúdica, mas que também fazia parte da cultura - ouvir história, contar, cantar músicas, encenar...

Ocorre uma implicação fundamental: toda arma que o trabalhador tiver para operar encontros tem que estar a serviço dos "movimentos em ato" de que um encontro é portador, não o contrário. Suas ferramentas tecnológicas só serão efetivamente tecnologias singularizadoras como encontros-acontecimento. (Cecim, Merhy, 2009, p.535)

Buscávamos o território da infância e da adolescência, deslocando-se a atenção da doença para a (re)significação de sujeitos e objetivando: (i) instituir um cotidiano, tramas relacionais e ritmos que fossem marcados pelos movimentos infantis e pelo lúdico como linguagem; (ii) possibilitar uma apropriação do espaço hospitalar e de suas marcas por meio da ação lúdica e da produção de narrativas de si e daquele universo; (iii) promover uma narrativa própria de si mesmo - criançaadolescente-(mãe)mulher - alguém que, em meio à processualidade da vida, experimentou a estada em um hospital.

As histórias contadas, memórias do humano, da cultura, da sociedade na qual se vive, retomavam a vivacidade do mundo na experiência pessoal: ser sujeito no mundo, ser parte de suas histórias e, assim, ter condição de modificá-las.

Observamos que, ao utilizarmos os espaços de convivência da enfermaria e sua brinquedoteca, a realização da contação de histórias inventava um lugar para o brincar dentro da estrutura hospitalar. Eram rodas, tendas, caminhadas atrás de uma música, de uma caixa, que ressignificavam os "verdes e brancos" da enfermaria. A constituição heterogênea dos participantes das atividades permitiu uma circulação de elementos culturais, afetivos, memórias que enriqueceram o que era possível trocar 
e se apropriar nas atividades. Uma história podia surgir de uma conversa, uma lembrança ou uma novidade, ativando um tempo-espaço de jogo, próprio da atividade lúdica e dos processos de criação.

Diante da complexidade do trabalho, usamos - como sugere Mehry $(2005,2000)$ - variadas tecnologias de nossas "valises", de modo a criar um território onde se operasse artesanalmente na construção de modos de cuidar. Localizávamos as diferentes matérias com que iríamos trabalhar e delicadamente desenhávamos a ação, apenas esboçada em seus contornos possíveis, resultando em produtos sempre singulares. Esta condução exigiu do terapeuta uma prontidão, uma valise que contivesse múltiplos repertórios, uma habilidade para inventar, recolocando o encontro com o outro como foco da ação terapêutica.

No encontro entre terapeuta e sujeito do cuidado, a atenção e o acolhimento eram gestos em direção ao outro, promovendo uma relação que se desdobrava em um processo atravessado por delicadezas. Delicadeza e disponibilidade para o encontro, no aproximar-se e no receber o outro, na localização e invenção de recursos e seus usos. No decorrer das ações de contar histórias, para promovermos uma grupalidade entre sujeitos que pouco se conheciam, de forma a tecer uma coletividade, necessitamos de ferramentas específicas, dentre elas, os ritos de começo. Assim, nos momentos iniciais da oficina, havia uma tensão no ar. Afinal, alguns participantes nem conheciam o ambiente do hospital; alguns nem sequer haviam saído do quarto até então. A instauração de um espaço-tempo para a história acontecer era o que inaugurava um lugar de conversa entre os sujeitos e as "coisas do hospital". Algumas vezes, cantava-se, em outros momentos, movimentava-se um tecido, tocava-se um instrumento ou fazia-se um gesto que produzia uma marca.

Cena 1. Neste dia, foi decidido que faríamos uma atividade com os adolescentes; a maioria das crianças estava dormindo e, então, não teria Oficina. Momentos depois, algumas crianças acordaram e, ao verem a caixa decorada da contação de histórias, chamaram-nos e, praticamente sozinhas, montaram um 'setting' sentando-se em círculo. A oficina teve que acontecer. (ACCALANTO, 2009, p.18)

Durante a realização da oficina, inventamos uma caixa de contar histórias que, frequentemente, foi suficiente para fazer o "momento" da história acontecer. A caixa de papelão, decorada com papel colorido, podia conter panos, fantoches, instrumentos musicais e material reciclável que se transformavam em personagens, compunham paisagens, constituindo uma realidade outra, mesmo que efêmera. Mas a caixa também podia estar vazia de todas estas coisas, sendo lugar onde o invisível e o imaginário também cabiam. Considerávamos, assim, a heterogeneidade da população e a circulação de sujeitos pela enfermaria, bem como o processo de formação em que se encontravam alguns dos terapeutas que conduziam a atividade. Buscávamos, também, novos modos de criar um repertório de objetos e histórias. Acreditamos que essa estratégia facilitou a improvisação no encontro com os participantes da oficina, o desenvolvimento de uma atenção singular ao grupo do dia e a instauração de outra ambiência. A partir da adoção de um olhar atento e aberto à relação e aos encontros, foi possível situar o cotidiano do cuidado em um campo singular na produção de saúde. Portanto, em alguns momentos, eram as situações cotidianas que se constituíram matéria de cuidado.

Cena 2. Vendo que as crianças estavam desenhando na brinquedoteca, adaptei a forma de contar conforme a atividade em processo. Tirei todos os lápis do pote que os guardava, deixando apenas um lápis amarelo. Contei que ela era uma margarida que sentia muito frio à noite. Depois de se utilizar de várias estratégias para não sentir frio, ela descobre que, com mais flores ao seu lado, ficaria aquecida. Então, as crianças me ajudam a aquecer a flor, recolocando um a um os lápis/flores no pote/vaso. E margarida volta a ficar aquecida e feliz. (ACCALANTO, 2010, p.39)

Mobilizar a produção de algo em comum, favorecer as trocas entre os participantes e apresentar um ao outro, intervindo para que, em estado de jogo, um coletivo pudesse surgir e se afirmar foram 
algumas das estratégias utilizadas. Buscávamos tecer artesanalmente maiores possibilidades de trocas e de construção de redes relacionais.

Observamos que as tramas vinculares disparadas e/ou alimentadas pela oficina se desdobraram em parcerias que permitiram uma apropriação do sentido de se "estar no hospital". Eram trocas que promoviam a tessitura de uma cotidianidade no hospital, contemplando formas de lidar com o sofrimento dos filhos, com a alimentação, banho e vestuário, com a espera do tempo de cada processo de cuidado acontecer. Eram descobertas de brincadeiras, de espaços para brincar, empréstimos de contratualidade na relação com os profissionais de saúde, e destes com os sujeitos do cuidado.

Foi passando aquele medo do medo que tinha do LOBO.

Foi ficando só com um pouco de medo daquele lobo.

Depois acabou o medo e ela ficou só com o lobo. (Buarque, 2006, s/p)

Neste sentido, o grupo que compartilhava histórias começava a produzir suas próprias narrativas com o hospital e seus ritmos, pessoas e coisas. Assim como na poesia-história de Chico Buarque, aquilo que parecia inacessível e ameaçador pôde se tornar familiar. As histórias acessavam e transversalizavam a experiência do humano, permitiam conectar lembranças, habilidades e vivências do dia a dia fora do ambiente hospitalar e resgatavam percursos pessoais e seus valores agregados, particularizando o ser de cada um. Com base nas delicadezas das narrativas que ali se trançavam, algumas vezes, foi possível adentrar universos muito próprios de referências e possibilitar que as narrativas comuns à linguagem dos profissionais de saúde se tornassem compreensíveis e assimiláveis a todos. Emprestava-se a língua, os dialetos, como parte daquilo que constituía um poder de trocas sociais.

Buscamos um ambiente vincular mais cooperativo, menos assimétrico na composição das relações. Notamos que estas estratégias abriram espaço para o que vimos nomeando como protagonismo. Os sujeitos puderam gestar modos de estabelecer o cuidado, compartilhando, com a equipe, seus processos de saúde-doença, apresentando ideias, maneiras de fazer junto, operando na (re)criação de si no enfrentamento de situações individuais e coletivas. Operou-se, portanto, no terreno da vida, em sua afetividade e pulsação. Neste sentido, abriram-se possibilidades de acesso a conteúdos diversos, vindos de outros lugares que não o de criança ou de adolescente hospitalizado, submetido a inúmeros procedimentos e restrito, impedido objetiva e/ou subjetivamente por incômodos das mais variadas ordens, como o espaço-tempo de permanência no ambiente hospitalar.

Cena 3. Quando eu sou o jacaré, não tenho medo de injeção, não dói - dirigindo-se às outras crianças do grupo, diz um menino com um fantoche de jacaré na mão. (ACCALANTO, 2009, p.23)

Cena 4. E. pintou algo que parecia com um cenário do Sertão (sua origem) e L. nomeou sua pintura com os termos "equilíbrio", "ponto de apoio" durante a atividade posterior à contação de história. (ACCALANTO, 2010, p.33)

Cena 5. O pai de N. chegou e perguntou como tinha conseguido fazer - tinha sido construído com ela um castelo de lego que, com sua varinha mágica, foi enfeitado com vários objetos (ela dava o comando, dizia as palavras mágicas e outra pessoa realizava a ação) - a menina estava com uma limitação nos braços. Respondemos dizendo ao pai que ela tinha poderes e a menina sorriu. (ACCALANTO, 2009, p.25) 
Por outro lado, a construção de novos tecidos relacionais afetou a todos os envolvidos no processo, levando-os a tal reflexão acerca dos processos de humanização do cuidado, que, em seu cerne, retomaram a condição de inventividade e apropriação do fazer também dos profissionais de saúde. Transmutando procedimentos e abordagens que poderiam ser considerados pontuais em ações de cuidar, engendraram-se novos valores e lugares sociais, promovendo uma cultura menos assimétrica entre profissionais e sujeitos da atenção.

Cena 6. Numa proposta de contação de história a partir dos desenhos das crianças, estávamos trabalhando com cores diferentes. Pedindo licença, uma enfermeira chegou e pediu a uma criança que tomasse um medicamento; este vinha numa seringa. Logo a criança disse o nome da cor do remédio - laranja - e, depois de explorar a sensação visual, tomou-o. Em seguida, a seringa também compôs a brincadeira à medida em que se tornou objeto de exploração; foi ressignificada. (ACCALANTO, 2010, p.42)

Observamos que as ações de cuidado também eram convocadas a serem repensadas a todo instante, na medida em que acenavam às multiplicidades complexas da atenção hospitalar. Ao mesmo tempo, tornavam-se narrativas de processos singulares que exprimiam os encontros entre profissionais de saúde, sujeitos do cuidado e ambientes diversos. Narrativas que compunham as "caixas de histórias" de cada um de seus personagens e nutriam as valises com diferentes dispositivos tecnológicos que podiam ser sempre reativados nesta ou naquela composição singular de uma história de cuidar.

Cada uma das cenas escolhidas, talvez, responda a uma pergunta que se fazia aos participantes da oficina, ao final de uma história; pergunta esta que compunha outra narrativa junto à caixa.

Em uma caixa muito especial onde se colocam objetos valiosos, de origens diferentes e repletos de significados... - Se pudesse guardar algo, o que guardaria? (ACCALANTO, 2009, p.21)

\title{
Considerações finais
}

\author{
... Entrou por uma porta e saiu pela outra... \\ E quem quiser que conte outra. \\ (Roveri, 2009, contracapa)
}

Num campo onde a intervenção exige uma qualidade de presença que vai além da atenção centrada em procedimentos e da aplicação de saberes técnicos normatizados, estratégias precisam ser inventadas para se promover acolhimento, escuta, afetações diversas e processos vinculares, tais como as que utilizamos na oficina de contação de histórias. Nesse sentido, é possível recolocar as ações do terapeuta ocupacional, que vão se construindo junto ao sujeito com o uso de ferramentas tecnológicas disponíveis.

Acreditamos que explorar as atividades lúdicas e o que pode ser chamado de tecnologias leves contribui para a produção de cuidados em terapia ocupacional no ambiente hospitalar, em consonância com os princípios da integralidade e da humanização do cuidado. São experiências que suscitam reflexões acerca das sutilezas e delicadezas do trabalho terapêutico ocupacional em um dispositivo de atenção à saúde, em que a vida está em seu estado de alerta máximo, no fio de seus limites, e onde, muitas vezes, o profissional se depara com a impotência devido à vulnerabilidade das condições de saúde e de adoecimento dos sujeitos. 


\section{Colaboradores}

As autoras participaram igualmente da redação do artigo.

\section{Referências}

ACCALANTO. Diário de atendimento. São Paulo: FMUSP/ACCALANTO, 2010. mimeogr.

. Diário de atendimento. São Paulo: FMUSP/ACCALANTO, 2009. mimeogr.

BENEVIDES, R.; PASSOS, E. A humanização como dimensão pública das políticas de saúde. Cienc. Saude Colet., v.10, n.3, p.561-71, 2005.

BROUGÈRE, G. A criança e a cultura lúdica. In: KISHIMOTO, T.M. (Org.). O brincar e suas teorias. São Paulo: Pioneira, 2002. p.19-32.

Brinquedo e cultura. São Paulo: Cortez, 1995.

BUARQUE, C. Chapeuzinho amarelo. Rio de Janeiro: José Olympio, 2006.

CASTRO, E.D. Inscrições da relação terapeuta-paciente no campo da terapia ocupacional. Rev. Ter. Ocup. Univ. São Paulo, v.16, n.1, p.14-21, 2005.

CECCIM, R.B.; MERHY, E.E. Um agir micropolítico e pedagógico intenso: a humanização entre laços e perspectivas. Interface - Comunic., Saude, Educ., v.13, suppl.1, p.531-42, 2009.

CECÍLIO, L.; MERHY, E.E. Integralidade do cuidado como eixo da gestão hospitalar. In: PINHEIRO, R.; MATTOS, R.A; CAMARGO, K. (Orgs.). Construção da integralidade, cotidiano, saberes e práticas em saúde. Rio de Janeiro: Abrasco, 2003. p.197-210.

DESLANDES, S. (Org.) Humanização dos cuidados em saúde: conceitos, dilemas e práticas. Rio de Janeiro: Fiocruz, 2006.

FURTADO, M.C. Brincar no hospital: subsídios para o cuidado de enfermagem. Rev. Esc. Enferm. USP, v.33, n.4, p.364-9, 1999.

GALHEIGO, S.M.; ANGELI, A.A.C. Terapia Ocupacional e o cuidado integral à saúde de crianças e adolescentes: a construção do Projeto ACCALANTO. Rev. Ter. Ocup. Univ. São Paulo, v.18, n.1, p.10-5, 2008.

KISHIMOTO, T.M. O jogo e a educação infantil. In: brincadeira e a educação. São Paulo: Cortez, 1996. p.13-43.

(Org.). Jogo, brinquedo,

MEHRY, E.E. Engravidando palavras: o caso da integralidade. In: PINHEIRO, R.; MATTOS, R.A. (Orgs.). Construção social da demanda. Rio de Janeiro: IMS/UERJ-Cepesc-Abrasco, 2005. p.195-206.

Saúde: a cartografia do trabalho vivo. São Paulo: Hucitec, 2002.

Um ensaio sobre o médico e suas valises tecnológicas: contribuições para compreender as reestruturações produtivas do setor saúde. Interface - Comunic., Saude, Educ., v.4, n.6, p.109-116, 2000.

MITRE, R.M.; GOMES, R. A perspectiva dos profissionais de saúde sobre a promoção do brincar em hospitais. Cienc. Saude Colet., v.12, n.5, p.1277-84, 2007.

A promoção do brincar no contexto da hospitalização infantil como ação de saúde. Cienc. Saude Colet., v.9, n.1, p.147-54, 2004.

MORAIS, G.S.N. O brincar na construção de um cuidado integral à criança hospitalizada. In: CONGRESSO BRASILEIRO DOS CONSELHOS DE ENFERMAGEM, 12., 1999, Belo Horizonte. Anais... Belo Horizonte, 1999. Disponível em: <http://189.75.118.67/ CBCENF/sistemainscricoes/arquivosTrabalhos/I11128.E3.T2317.D3AP.pdf>. Acesso em: 29 mar. 2010. 
PEDROSA, A.M. et al. Diversão em movimento: um projeto lúdico para crianças hospitalizadas no Serviço de Oncologia Pediátrica do Instituto Materno Infantil Prof. Fernando Figueira, IMIP. Rev. Bras. Saude Matern. Infant., v.7, n.1, p.99-106, 2007.

PENGO, M.M.; SANTOS, W.A. O papel do Terapeuta Ocupacional em Oncologia. In: DE CARLO, M.M.; LUZO, M.C. (Orgs.) Terapia Ocupacional: reabilitação física e contextos hospitalares. São Paulo: Roca, 2004. p.233-55.

ROSSIT, R.A.; KOVÁCS, A.C. Intervenção essencial de terapia ocupacional em enfermaria pediátrica. Cad. Ter. Ocup. UFSCar, v.7, n.2, p.58-67, 1998.

ROVERI, S. Tatiana Belinky. São Paulo: Imprensa Oficial, 2009.

SAFRA, G. Desvelando a memória do humano: o brincar, o narrar, o corpo, o sagrado, o silêncio. São Paulo: Sobornost, 2006.

WINNICOTT, D.W. O brincar e a realidade. Rio de Janeiro: Imago, 1975. 
O objetivo deste trabalho é refletir sobre os modos de fazer, sentir e conduzir as ações de contar histórias em uma enfermaria pediátrica. Essas ações decorrem de atividades de extensão universitária, no âmbito da terapia ocupacional. A reflexão, realizada a partir da revisão de literatura e discussão sobre anotações de campo do projeto, pautase por norteadores teóricos baseados nas tecnologias do cuidado e no brincar dentro do contexto das intervenções no hospital, sob a perspectiva da integralidade e da humanização do cuidado. A contação de histórias é apresentada enquanto forma de promover escuta, acolhimento, afetações diversas e processos vinculares, possibilitando a constituição de uma rede de sustentabilidade relacional, envolvendo os atores que circulam na enfermaria. Reafirma, assim, as práticas profissionais em saúde no hospital a partir de uma construção permanente junto ao sujeito por meio de ferramentas tecnológicas singularizadoras que promovam encontros-acontecimentos.

Palavras-chave: Integralidade. Humanização. Cuidado. Terapia Ocupacional. Atividade lúdica.

Day-to-day life, play and relational networks: the handcrafting of care in occupational therapy in hospitals.

The aim of this study was to reflect on the ways of doing, feeling and conducting storytelling actions in a pediatric ward. These practices resulted from university extension activities within the scope of occupational therapy. This reflection was done by reviewing the literature and discussing field notes on the project, and was based on a theoretical framework grounded in care technologies and in play within the context of hospital interventions, from the perspective of comprehensive and humanized care. Storytelling is presented as a means of promoting listening, reception, different affectations and bonding processes, thereby making it possible to set up a support network among the players present in the ward. It thus reaffirms professional healthcare practices in the hospital through continual construction among the subjects by using individualized technological tools that promote meetings and happenings.

Keywords: Comprehensiveness. Humanization. Care. Occupational therapy. Play activity.

La vida cotidiana, el juego y la red de relaciones: la artesania del cuidado en terapia ocupacional en el hospital.

Este trabajo reflexiona sobre las formas de hacer, sentir y conducir la narración de historias en una enfermería de pediatría. Estas acciones se derivan de las actividades de extensión universitaria en terapia ocupacional. Esta reflexión, a partir de revisión de la literatura y la discusión de las notas de campo del proyecto, se orienta en las teorías de la tecnología del cuidado y en el juego dentro del contexto de las intervenciones en el hospital, desde el punto de vista de la integralidad y la humanización de la atención. Presenta la narración de historias como una forma de promover escucha, acogida, cambios y vínculo, lo que permite la creación de una red de apoyo con los que circulan en la enfermería. Reafirma así las prácticas profesionales en salud en el hospital a través de herramientas tecnológicas que promuevan singulares encuentros-evento.

Palabras clave: Integralidad. Humanización. Atención. Terapia Ocupacional. Juego. 
